\title{
Design of a Rigid-frame Steel Truss Arch Bridge
}

\author{
Yufeng $\mathrm{Xu}^{1}$, Junsheng Chen ${ }^{1,}{ }^{*}$, Yue $\mathrm{Li}^{2}$ \\ 1. State Key Laboratory of Subtropical Building Science, South China University of Technology, \\ Guangzhou 510640, China; \\ ${ }^{2}$ Guangzhou Xinguang Expressway Ltd. Co. Guangzhou, China. \\ *jschen@scut.edu.cn
}

Keywords: Xinguang Bridge, Steel truss arch, Triangular rigid frame, Horizontal ties, Vertical Suspender.

\begin{abstract}
The Xinguang Bridge, crossing the shipping channel of the Pearl River in the city of Guangzhou, is a three-span continuous half-through rigid frame steel truss arch bridge with two RC $\mathrm{V}$-shaped triangular rigid frames. The paper first gives a brief introduction on the important engineering aspects. Then the characteristics of this bridge such as the supporting system, structure of the deck system, horizontal tie, arch rib, vertical suspender, V-shaped triangular rigid frame, and foundation are investigated herein are given detailed demonstration. The conclusions and future prospects are finally presented.
\end{abstract}

\section{Introduction}

The Xinguang Bridge, crossing the shipping channel of the Pearl River in the city of Guangzhou, is a three-span continuous half-through rigid frame steel truss arch bridge with two RC V-shaped triangular rigid frames [1] (See Figure 1.). The bridge has a total length of $1083.2 \mathrm{~m}$. The total length of 3 spans of the main bridge is $177 \mathrm{~m}+428 \mathrm{~m}+177 \mathrm{~m}=782 \mathrm{~m}$. The main bridge is $37.22 \mathrm{~m}$ wide for six traffic lanes and two sidewalks. When it was open to traffic in January 2007, Xinguang Bridge had the 6th-longest arch span in the world and had the 3rd-longest arch span $(428 \mathrm{~m})$ in China. The general data for design is presented in Table 1.

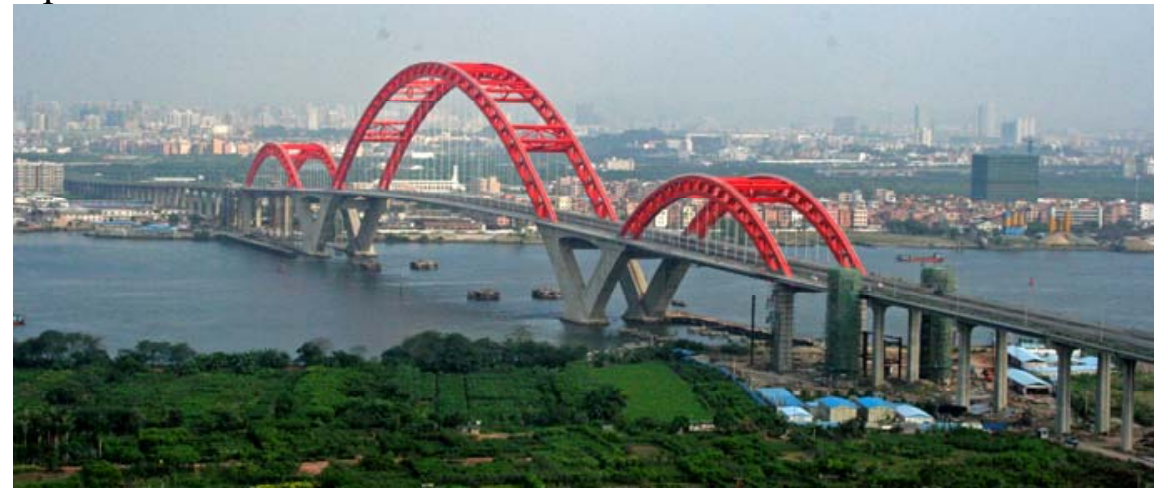

Figure 1. Illustrative view of Xingguang Bridge

\section{Special Aspects of the Design of the Main Bridge}

The Xinguang Bridge, crossing the shipping channel of the Pearl River, is located in the central axis of Guangzhou New City. The design of the bridge was dominated by the aim to develop a landmark. By a close cooperation between the owner, the design engineer and the construction engineer, a harmonic design of the entire crossing has been achieved. The bridge, which spans the Pearl River like a flying rainbow representing the development of the economies in Guangzhou, incorporates a number of innovations and first applications in China like the special bridge structural system, non-conventional constructional details, and the erection method. The special design aspects of major importance can be summarized as follows. 
Table 1. General data

\begin{tabular}{|c|c|}
\hline Design speed: & $80 \mathrm{~km} / \mathrm{h}$ \\
\hline Design load: & Vehicular load: Truck-20T \\
Trailer-120T \\
Crowd load:4.0kN/m2
\end{tabular}

\subsection{Foundation}

Foundations for the main bridge are supported on end-bearing cast-in-place bored piles anchored in solid rock layer. As shown in Figure 2, in the case of main span, the foundation consists of 36 bored tube bored piles of $2.6 \mathrm{~m}$ diameter, and the pile cap has a size of $48.3 \mathrm{~m}$ in transverse direction, $34.7 \mathrm{~m}$ in longitudinal direction of the bridge, and $6 \mathrm{~m}$ in thickness, while for the side span, each of the two tie-down pile caps having a size of $11.6 \mathrm{~m}$ by $11.6 \mathrm{~m}$ and thickness of $3.5 \mathrm{~m}$ are supported by 9 cast-in-place bored piles of $2.0 \mathrm{~m}$ diameter.

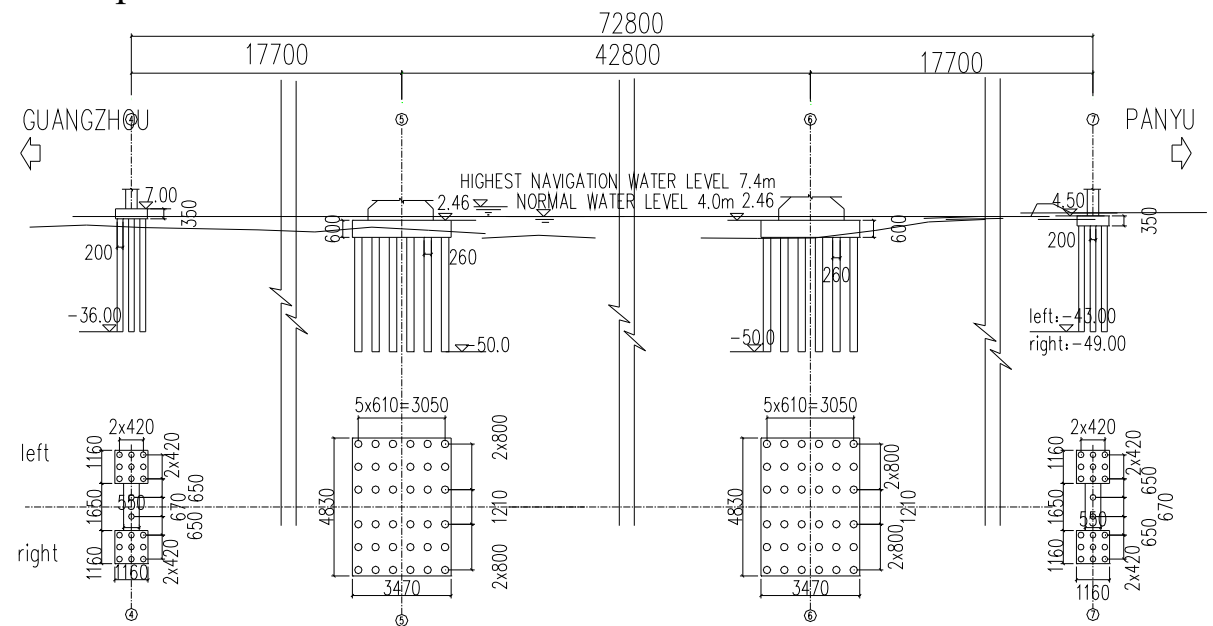

Figure 2. Elevation view and top view of foundation (unit: $\mathrm{cm}$ )

\subsection{V-shaped Triangular Rigid Frame for the Main Pier}

The V-shaped triangular rigid frame (See Figure 3) as the connections between the center span and side spans provide large stiffness, good seismic performance, and better resistance against possible ship collision capability [2]. In addition, the rigid frame provides its capabilities in resisting the 
moment imbalance in construction, which simplified the construction procedures and decreased the live load influences between side span and main span. The tied beam of the triangular rigid frame is a PC solid L cross-sectional structure with a width of $5600 \mathrm{~mm}$ and a height of $3000 \mathrm{~mm}$. 34 post-tensioned, injected tendons are installed into the tied beam of the frame, and each tendon consists of $31-7 \varphi 5$ strands.

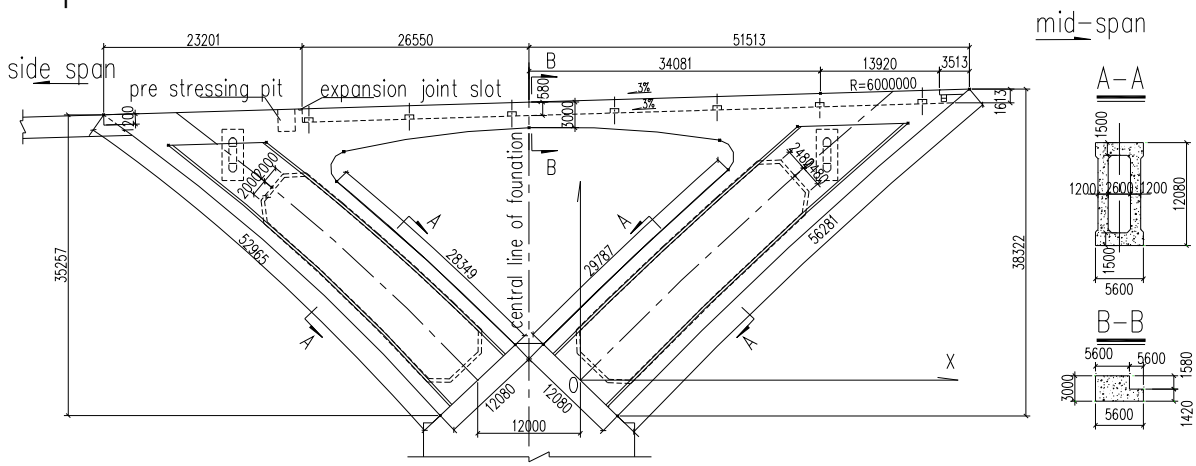

\subsection{Arch Rib}

Figure 3. Elevation view of Triangular Rigid Frame (unit: mm)

The arch ribs of the mid-span with a span of $428 \mathrm{~m}$ (clear span length: $416 \mathrm{~m}$ ) and a height of $104 \mathrm{~m}$ follow a catenary with an arch axis coefficient of $\mathrm{m}=1.2$ and a ratio of rise to arch span to of 1/4. These two steel arch ribs are spaced at an interval of $28.1 \mathrm{~m}$ from centerline to centerline. Each of these arch ribs has a depth varying from $7.50 \mathrm{~m}$ at the crown to $12.0 \mathrm{~m}$ at the spring. The top and bottom chords with rectangular box girder cross-sections have thicknesses of $30 \mathrm{~mm}$ and $50 \mathrm{~mm}$ for steel webs and thicknesses of $32 \mathrm{~mm}, 40 \mathrm{~mm}, 50 \mathrm{~mm}$ for the top and bottom plates of the girder. [3]

The steel arch ribs of the side span with a span of $177 \mathrm{~m}$ (clear span length: $171 \mathrm{~m}$ ) and a height of $56 \mathrm{~m}$ follow a 3 -order parabola with a depth varying from $7.50 \mathrm{~m}$ at the crown to $12.0 \mathrm{~m}$ at the spring. The steel box girders of the cross section have thicknesses of $24 \mathrm{~mm}, 32 \mathrm{~mm}$ and $36 \mathrm{~mm}$ for steel webs and thicknesses of $30 \mathrm{~mm}, 36 \mathrm{~mm}$, and $40 \mathrm{~mm}$ for the top and bottom plates of the girder, respectively.

The integrated node connection technique is employed to fabricate the steel arch ribs. The chords of the arch ribs, as a welded and bolted structure, are connected in the node position via an integrated node plate which is formed by changing the height and thickness of the steel webs. The longitudinal ribs inside the steel box girder and cross section of arch chord are connected using high-strength bolts and field welding, respectively, while the braces are connected to the chords via high-strength bolts.

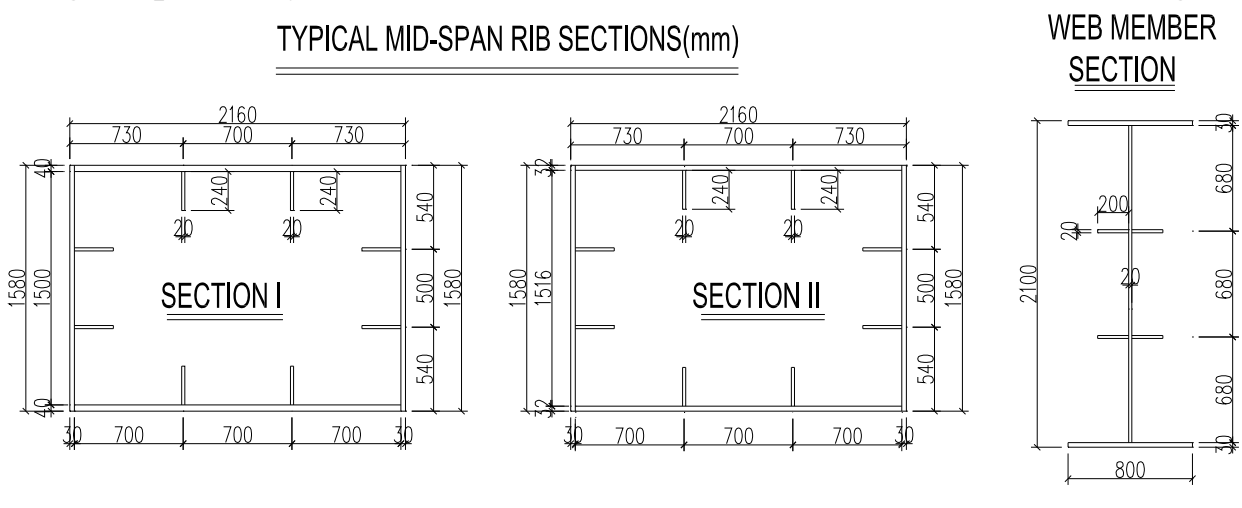

Figure 4. Typical cross section of the arch ribs of main span (unit: $\mathrm{mm}$ )

\subsection{Horizontal Ties}

8 adjustable OVM horizontal ties with 199- $\$ 7$ parallel steel wires, Hi-Am type sockets, and stress-released protection HDPE layer are placed at the deck level between the two ends of each arch rib of mid-span to balance the horizontal force induced by arch rib. The tie cables can be replaced one by one. 16 post-tensioned, injected tendons are installed into each PC longitudinal beams (also as the horizontal ties) of side span, and each tendon consists of $27-7 \varphi 5$ strands. The stiffened horizontal tie has a height of $2500 \mathrm{~mm}$ and a width of $2100 \mathrm{~mm}$. 


\subsection{Vertical Suspender}

The new types of OVM cable system, composed of galvanized parallel wire strands, Hi-Am type sockets, and stress released HDPE protection layer, is employed for the vertical suspenders. The upper end of each suspender penetrates the bottom plate of the arch rib and is anchored at a diaphragm inside the box rib while the bottom end is anchored to the transverse beam. Two short suspenders in each end of the main arch and side arches are specially designed to be a hinged and enlarged structure capable of releasing the deformation and horizontal displacement and decreasing its stress amplitude. The suspenders in the center and end of the main span consist of 139- $\phi 7$ and 187- $\phi 7$ galvanized parallel steel wires, respectively. In the case of side spans, the suspenders in the center and end of the span consist of 187- $\phi 7$ and 313- $\phi 7$ galvanized parallel steel wires, respectively.

\subsection{Bearing System of the Main Bridge}

Compared with the conventional "flying-bird" three-span arch bridge with a half-through center span, two side spans under deck, and horizontal cables balancing the horizontal thrust of the center arch span, the innovative structure of the main bridge introduces the $\mathrm{V}$-shaped triangular rigid frame as the connections between the center span and side spans. As shown in Figure 1, one end of the side arch is fixed in the V-shaped triangular rigid frame, while another end is supported on the side pier via a movable spherical steel bearing capable of $200 \mathrm{~mm}$ longitudinal displacement, which makes it possible to release the thermal stress with the help of deck expansion joint. Moreover, the chord members of arch ribs of the main span are directly embedded in the triangular rigid frame, which can significantly enhance the structural stiffness and makes it no need to install the expensive bearings. [4].

\subsection{Deck System of the Main Span: Semi-floating System}

The novel structure can fully take advantage of not only the superior capacity of load carrying system of the steel truss arch but also the large stiffness and good seismic performance of the triangular rigid frame. Note that the horizontal stiffness of the rigid frame is notable. To release the structural thermal deformation-induced strong horizontal force of the deck system the deck structure of center span of the main bridge is designed to be a horizontal movable semi-floating system in the longitudinal direction. The deck structure is designed to be supported by steel transverse beam via suspenders hanged to ribs and by spherical steel bearing to triangular rigid frame. Furthermore, two expansion joints between the deck connection of center span and side span are installed to release the thermal stress.

\subsection{Structure of the Deck System}

As shown in Figure 1, to attain to an ideal moment balance of the triangular rigid frame and the foundation, the longitudinal beam and the lateral beam of the two side spans are designed to be a prestressed concrete structure, respectively, whereas those of the main span are carefully designed to be steel structure. The expansion joints are the borderlines of the side decks and mid-deck. [5]

As represented in Figure 5, the deck structure of the main span is a lattice girder system which is made up of 41 steel transverse beams and 9 steel longitudinal beams. The pre-cast reinforced concrete slabs are then rigidly connected to the lattice girders to form a steel-concrete composite structure. The webs and bottom wings of the steel longitudinal beam are field bolted using high-strength steel bolts while the top wings of them are field welded to the transverse beam. In the case of side span, the stiff PC tie (also regarded as the longitudinal beam), the PC transverse beams, the secondary longitudinal $\mathrm{RC}$ beams, and RC bridge slabs are employed to enhance the structural stiffness of the deck system. 


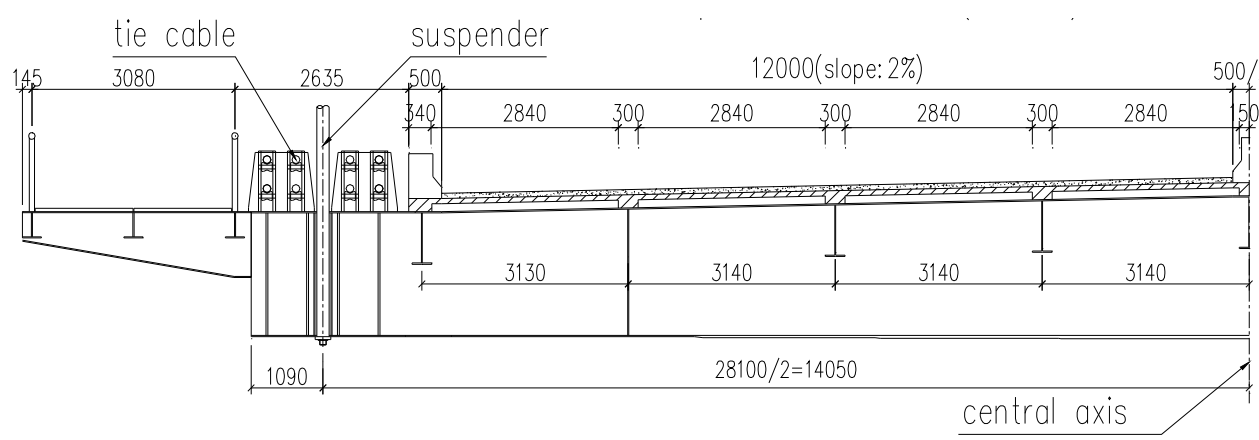

a. Cross section of the main span (unit: $\mathrm{mm}$ )

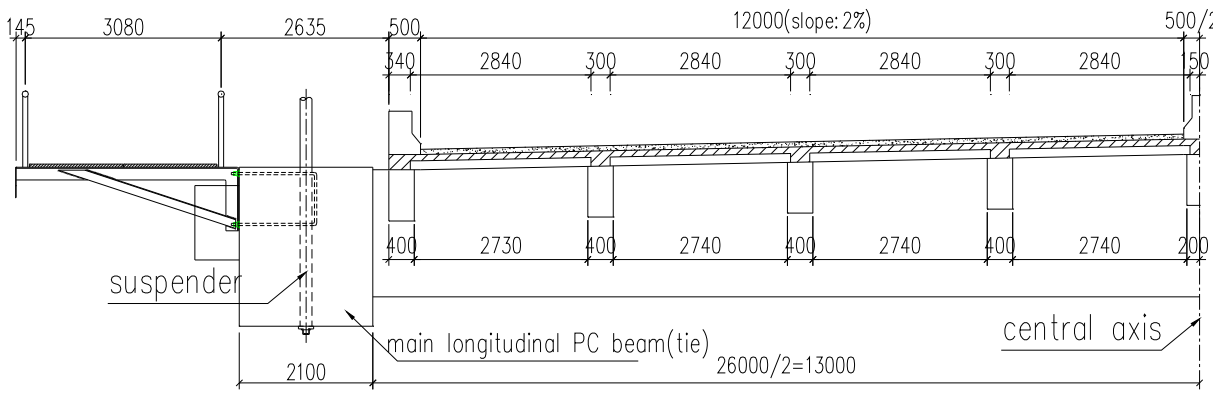

b. Cross section of the side span (unit: $\mathrm{mm}$ )

Figure 5. Deck system

\section{Conclusion}

An innovative design for the Xinguang Bridge was developed on the basis of the traditional half-through truss arch bridge solution, incorporating the typical V-shaped triangular rigid frames. The shape appearance, color application, and structural mechanic characterization are carefully considered to design a novel structure. Consequently, the design of Xinguang Bridge illustrative a valuable example to other long-span arch bridge's design.

\section{Acknowledgments}

Foundation item: Natural Science Foundation of China; State Key Laboratory of Subtropical Building Science, South China University of Technology; supported by the Fundamental Research Funds for the Central Universities.

\section{References}

[1]. China Railway Engineering Consultants Group Co., Ltd, Guangzhou Xinguang Expressway Engineering Xinguang Bridge Design of Construction, 2004, 8.

[2]. Li Yue,Xu Yufeng,Tan Lin, Simulation Analysis of Triangle Frame Construction Process of Xinguang Bridge[J], Journal of China \& Foreign Highway,2008,(1):81-84.

[3]. Xu Yufeng,Tan Lin, Li Jing,Su Cheng, Li Yue, Simulation Analysis of Global Construction Process of Main Bridge of Xinguang Bridge[J], Bridge Construction,2008,(06).

[4]. Liu Hongwei, Structure Research on Xinguang Arch Bridge[D], Dalian:Dalian University of Technology,2004.

[5]. Li Hui, Xu Shengqiao,Zhang Hua,Ren Weidong, Research on Bridge Surface Design of Steel-Concrete Bond Beam in Main Span of Xinguang Bridge[J], Railway Investigation and Surveying,2007,(1). 